Supporting Information

\title{
Emission Trend of Multiple Self-Trapped Excitons in Luminescent 1D Copper Halides
}

\author{
Mao-Hua Du \\ Materials Science and Technology Division, Oak Ridge National Laboratory, Oak \\ Ridge, TN 37831, USA
}




\section{Computational Methods}

Our calculations are based on density functional theory with the hybrid PBE0 functional ${ }^{1}$ as implemented in the VASP code. ${ }^{2}$ The interaction between ions and electrons is described by projector augmented wave method. ${ }^{3}$ The kinetic energy cutoff of $369 \mathrm{eV}$ is used for the plane-wave basis. $\mathrm{CsCu}_{2} \mathrm{X}_{3}(\mathrm{X}=\mathrm{Cl}, \mathrm{Br}, \mathrm{I})$ have a base-centered orthorhombic structure with the space group $\mathrm{cmcm}$ (\#63). Experimental lattice parameters $\left(\mathrm{a}=9.4981 \AA, \mathrm{b}=11.8868 \AA, \mathrm{c}=5.5944 \AA\right.$ for $\mathrm{CsCu}_{2} \mathrm{Cl}_{3} ; \mathrm{a}=9.8712 \AA, \mathrm{b}$ $=12.3478 \AA, \mathrm{c}=5.8132 \AA$ for $\mathrm{CsCu}_{2} \mathrm{Br}_{3} ; \mathrm{a}=10.5479 \AA, \mathrm{b}=13.1725 \AA, \mathrm{c}=6.0972 \AA$ for $\mathrm{CsCu}_{2} \mathrm{I}_{3}{ }^{4}$ ) are used while the atomic positions are fully relaxed until the residual forces are less than $0.02 \mathrm{eV} / \AA$. A $1 \times 1 \times 3$ supercell is used for exciton calculations.

The optimized ground- and excited-state structures as well as the exciton emission energy are obtained by using the hybrid PBE0 functional, ${ }^{1}$ which has $25 \%$ non-local Fock exchange. The occupation numbers of the electron- and hole-occupied eigenlevels are fixed $\left[\Delta\right.$ self-consistent field $(\Delta \mathrm{SCF})$ method $\left.^{5-7}\right]$ for the total energy calculation of an exciton and throughout the entire excited-state structural relaxation process. The $\triangle \mathrm{SCF}$ method can be easily used for the self-trapped excitons (STEs) in $\mathrm{CsCu}_{2} \mathrm{X}_{3}(\mathrm{X}=\mathrm{Cl}, \mathrm{Br}, \mathrm{I})$ because the electron and hole are both strongly localized and each occupies one single eigenlevel deep inside the band gap. ${ }^{8}$ Unlike the exciton calculations based on the Bethe-Salpeter Equation ${ }^{9}$, which does not provide forces, the $\triangle \mathrm{SCF}$ method combined with the hybrid PBE0 functional allow the accurate calculation of excited-state structural relaxation, and the emission energy of a STE at an excitedstate energy minimum can be calculated based on the relaxed exciton structure 
following the Franck-Condon principle. The calculated STE emission energies in many compounds have shown excellent agreement with the experimental results. ${ }^{10-11}$

\section{Structures and Electronic Structures of $\mathrm{CsCu}_{2} \mathrm{X}_{3}(\mathrm{X}=\mathrm{Cl}, \mathrm{Br}, \mathrm{I})$ at the Ground}

State

The $\mathrm{Cu}-\mathrm{X}(\mathrm{X}=\mathrm{Cl}, \mathrm{Br}, \mathrm{I})$ bond lengths calculated by the $\mathrm{PBE}^{12}$ and $\mathrm{PBE} 0$ functionals are in good agreement with experimental results ( $<2 \%$ error) (see Table S1). However, the bond angle errors for $\mathrm{CsCu}_{2} \mathrm{Br}_{3}$ and $\mathrm{CsCu}_{2} \mathrm{I}_{3}$ are significant in the $\mathrm{PBE}$ calculation, resulting in an artificially short $\mathrm{Cu} 1-\mathrm{Cu} 2$ distance $(14 \%$ and $13 \%$ errors, respectively, more details in Table $\mathrm{S} 1$ ). The $\mathrm{Cu} 1$ and $\mathrm{Cu} 2$ atoms are shown in Fig. 1. The shortened $\mathrm{Cu} 1-\mathrm{Cu} 2$ distance enhances the intra-conduction-band s-s coupling and the cross-band-gap s-d coupling; the former decreases the band gap while the latter increases the band gap. Thus, the PBE-calculated band gaps of $\mathrm{CsCu}_{2} \mathrm{Br}_{3}$ and $\mathrm{CsCu}_{2} \mathrm{I}_{3}$ are not well behaved; the error depends on the details in the errors in s-s and s-d couplings originated from the incorrect $\mathrm{Cu} 1-\mathrm{Cu} 2$ distance. The artificially short $\mathrm{Cu} 1-$ $\mathrm{Cu} 2$ distance in the PBE calculation should be related to the self-interaction error. A short $\mathrm{Cu} 1-\mathrm{Cu} 2$ enhances delocalization of $\mathrm{Cu}-3 \mathrm{~d}$ orbitals, reducing the self-interaction error. The PBE-calculated $\mathrm{Cu} 1-\mathrm{Cu} 2$ distance is shortest in $\mathrm{CsCu}_{2} \mathrm{Br}_{3}$ (Table $\mathrm{S} 1$ ); this anomalous trend is likely due to a trade-off between ionicity and covalency. The higher ionicity in $\mathrm{CsCu}_{2} \mathrm{Cl}_{3}$ results in a stronger Coulomb repulsion between $\mathrm{Cu} 1$ and $\mathrm{Cu} 2$ cations while the stronger covalency in $\mathrm{CsCu}_{2} \mathrm{I}_{3}$ results in more electron distribution on the $\mathrm{Cu}$-I bonds, which repel each other. The hybrid PBE0 calculation significantly 
improves the calculated $\mathrm{Cu} 1-\mathrm{Cu} 2$ distance as shown in Table S1.
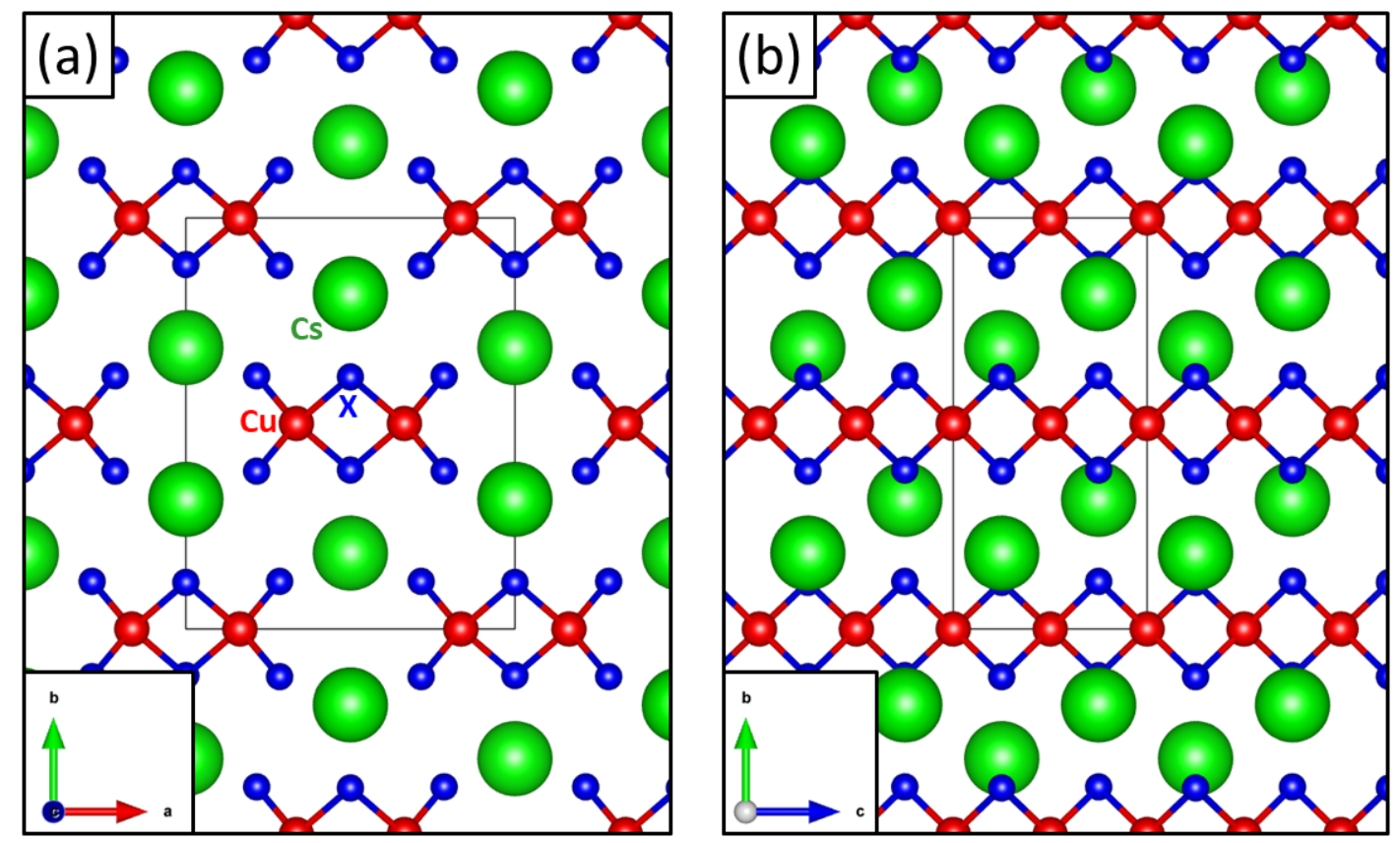

Fig. S1 Crystal structure of $1 \mathrm{D} \mathrm{CsCu}_{2} \mathrm{X}_{3}(\mathrm{X}=\mathrm{Cl}, \mathrm{Br}, \mathrm{I})$ viewed from the $\mathrm{c}$ and a axes (along and perpendicular to the 1D Cu halide atomic chains, respectively). Green, red, and blue balls represent $\mathrm{Cs}, \mathrm{Cu}$, and $\mathrm{X}(\mathrm{X}=\mathrm{Cl}, \mathrm{Br}, \mathrm{I})$ atoms, respectively. 

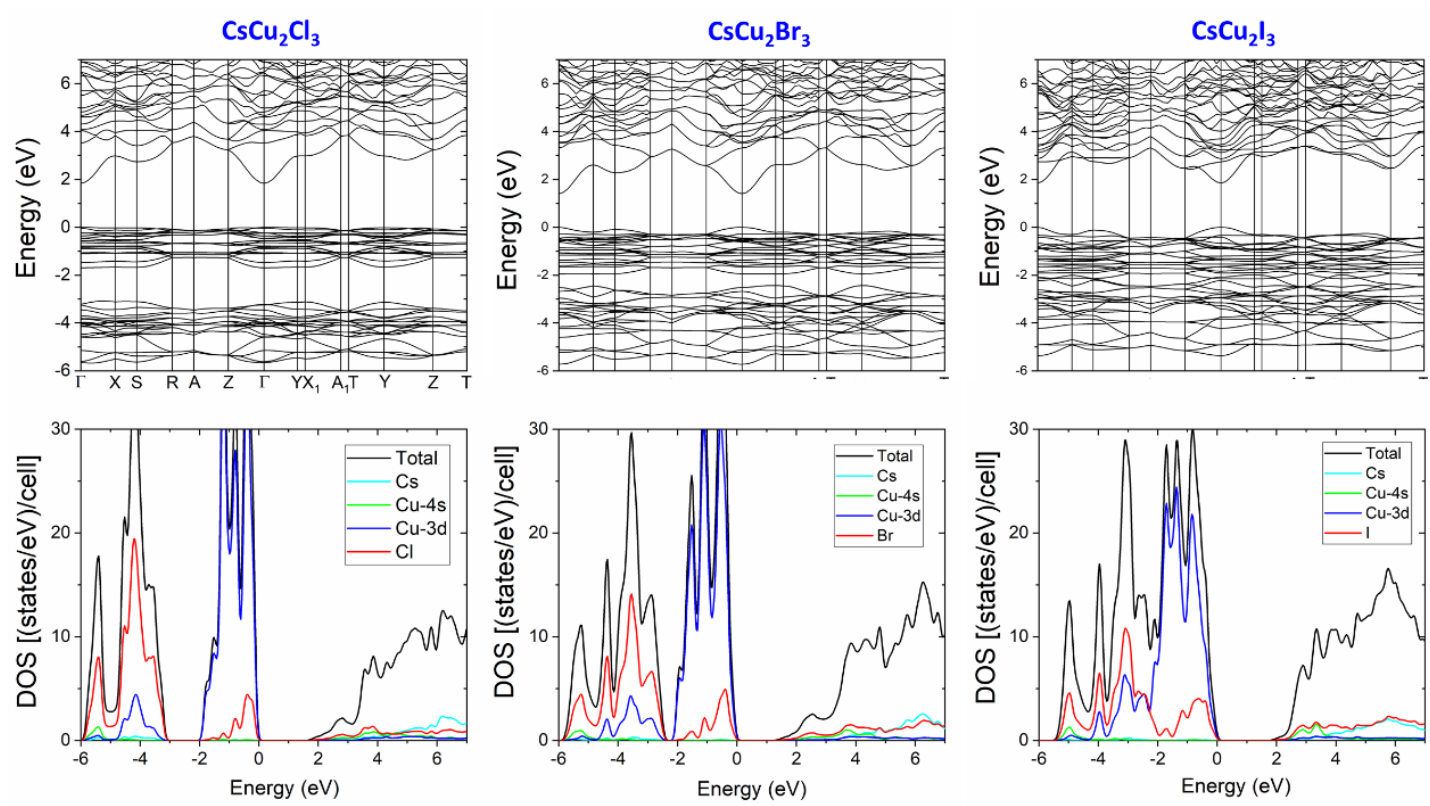

Fig. S2. Electronic band structure and projected density of states for $\mathrm{CsCu}_{2} \mathrm{Cl}_{3}$, $\mathrm{CsCu}_{2} \mathrm{Br}_{3}$, and $\mathrm{CsCu}_{2} \mathrm{I}_{3}$ calculated at the PBE level. The calculated PBE band gaps are underestimated.

Table S1. Bond lengths (in $\AA$ ) obtained by PBE and PBE0 calculations and by the experiment. The $\mathrm{X}_{\mathrm{IV}}$ and $\mathrm{X}_{\mathrm{II}}$ are the four-fold and two-fold coordinated halogen atoms shown in Fig. 1. The $\mathrm{Cu}-\mathrm{Cu}$ distance corresponds to the distance between the $\mathrm{Cu} 1$ and $\mathrm{Cu} 2$ atoms in Fig. 1. The experimental results are from Ref. 4.

\begin{tabular}{|l|c|c|c|c|c|c|c|c|c|c|}
\hline & \multicolumn{3}{|c|}{ Exp. } & \multicolumn{3}{c|}{ PBE } & \multicolumn{3}{c|}{ PBE0 } \\
\cline { 2 - 10 } & $\mathrm{Cu}-\mathrm{X}_{\mathrm{IV}}$ & $\mathrm{Cu}-\mathrm{X}_{\mathrm{II}}$ & $\mathrm{Cu}-\mathrm{Cu}$ & $\mathrm{Cu}-\mathrm{X}_{\mathrm{IV}}$ & $\mathrm{Cu}-\mathrm{X}_{\mathrm{II}}$ & $\mathrm{Cu}-\mathrm{Cu}$ & $\mathrm{Cu}-\mathrm{X}_{\mathrm{IV}}$ & $\mathrm{Cu}-\mathrm{X}_{\mathrm{II}}$ & $\mathrm{Cu}-\mathrm{Cu}$ \\
\hline $\mathrm{CsCu}_{2} \mathrm{Cl}_{3}$ & 2.490 & 2.273 & 3.119 & 2.484 & 2.278 & 3.189 & 2.468 & 2.284 & 3.175 \\
& & & & & & & & & \\
\hline $\mathrm{CsCu}_{2} \mathrm{Br}_{3}$ & 2.571 & 2.427 & 3.080 & 2.542 & 2.470 & 2.648 & 2.558 & 2.432 & 3.104 \\
\hline $\mathrm{CsCu}_{2} \mathrm{I}_{3}$ & 2.703 & 2.604 & 3.143 & 2.662 & 2.647 & 2.736 & 2.670 & 2.630 & 2.944 \\
\end{tabular}




\section{References}

1. Perdew, J. P.; Emzerhof, M.; Burke, K., Rationale for mixing exact exchange with density functional approximations. Journal of Chemical Physics 1996, 105 (22), 9982 9985.

2. Kresse, G.; Furthmüller, J., Efficiency of ab-initio total energy calculations for metals and semiconductors using a plane-wave basis set. Computational Materials Science 1996, 6 (1), 15-50.

3. Kresse, G.; Joubert, D., From ultrasoft pseudopotentials to the projector augmented-wave method. Physical Review B 1999, 59 (3), 1758.

4. Hull, S.; Berastegui, P., Crystal structures and ionic conductivities of ternary derivatives of the silver and copper monohalides-II: ordered phases within the $(\mathrm{AgX}) \mathrm{x}-(\mathrm{MX}) 1-\mathrm{x}$ and $(\mathrm{CuX}) \mathrm{x}-(\mathrm{MX}) 1-\mathrm{x}(\mathrm{M}=\mathrm{K}, \mathrm{Rb}$ and $\mathrm{Cs} ; \mathrm{X}=\mathrm{Cl}, \mathrm{Br}$ and $\mathrm{I})$ systems. Journal of Solid State Chemistry 2004, 177 (9), 3156-3173.

5. Jones, R. O.; Gunnarsson, O., The density functional formalism, its applications and prospects. Reviews of Modern Physics 1989, 61 (3), 689-746.

6. Görling, A., Density-functional theory beyond the Hohenberg-Kohn theorem. Physical Review A 1999, 59 (5), 3359-3374.

7. Hellman, A.; Razaznejad, B.; Lundqvist, B. I., Potential-energy surfaces for excited states in extended systems. The Journal of Chemical Physics 2004, 120 (10), 45934602.

8. Han, D.; Shi, H.; Ming, W.; Zhou, C.; Ma, B.; Saparov, B.; Ma, Y.-Z.; Chen, S.; Du, M.-H., Unraveling luminescence mechanisms in zero-dimensional halide perovskites. Journal of Materials Chemistry C 2018, 6 (24), 6398-6405.

9. Salpeter, E. E.; Bethe, H. A., A Relativistic Equation for Bound-State Problems. Physical Review 1951, 84 (6), 1232-1242.

10. Zhou, C.; Lin, H.; He, Q.; Xu, L.; Worku, M.; Chaaban, M.; Lee, S.; Shi, X.; Du, M.-H.; Ma, B., Low dimensional metal halide perovskites and hybrids. Materials Science and Engineering: R: Reports 2019, 137, 38-65.

11. Du, M.-H., Microscopic origin of multiple exciton emission in low-dimensional lead halide perovskites. The Journal of Chemical Physics 2019, 151 (18), 181101.

12. Perdew, J. P.; Burke, K.; Ernzerhof, M., Generalized gradient approximation made simple. Physical review letters 1996, 77 (18), 3865. 